\title{
Descobrindo a língua: as relações entre fala e escrita no processo de aquisição da linguagem
}

\author{
Willamy Matos dos SANTOS (D \\ Universidade Federal do Ceará (UFC)
}

\section{RESUMO}

A Associação Brasileira de Linguística (Abralin), durante o período da pandemia, em 2020, promoveu uma série de mesas-redondas, transmitidas ao vivo pelo canal da associação no YouTube. O objetivo desta resenha é apresentar a mesa redonda: A criança e o uso da língua: fala, escrita e suas relações na aquisição da linguagem, que abordou o emprego da língua pela criança enquanto falante e escrevente. No primeiro momento, o professor Lourenço Chacon apresentou dados não convencionais da escrita infantil de modo a observar a relação fala/oralidade e escrita/letramento. Em seguida, a professora Marlete Diedrich explorou a aquisição da linguagem como uma experiência de significação a partir de uma perspectiva enunci-

EDITADO POR ativa, baseada nos postulados de Benveniste (2005). Por fim, a professora Gabriela Maria de Oliveira-Codinhoto apresentou uma proposta funcionalista de textos infantis com ênfase na frequência de utilização de orações relativas em produções textuais de crianças.

\section{ABSTRACT}

The Brazilian Linguistics Association (ABRALIN) promoted a series of online roundtables during the pandemic time in 2020. The aim of this paper is to present a review of the Children and the use of language: speech, writing and its relation to language acquisition roundtable, which emphasized the use of language by children as speakers and writers. Initially, Professor Lourenço Chacon presented unconventional data on children's writing in order to observe the relationships between speech/orality and writing/literacy. Then, Professor Marlete Diedrich explored language 


\section{REVISTA DA ABRALIN}

acquisition as an experience of meaning from an enunciative perspective, based on the postulates of Benveniste (2005). Finally, Professor Gabriela Maria de Oliveira-Codinhoto presented a functionalist proposal for children's texts with an emphasis on the frequency of use of relative clauses in textual productions.

\section{PALAVRAS-CHAVE}

Aquisição da Linguagem. Linguística. Letramento.

\section{KEYWORDS}

Language Acquisition. Linguistics. Literacy.

Neste texto, resenhamos a mesa redonda intitulada A criança e o uso da língua: fala, escrita e suas relações na aquisição da linguagem, realizada no dia 17 de julho de 2020, como parte da série de transmissões ao vivo promovidas pela Associação Brasileira de Linguística (Abralin) em cooperação com diversas associações internacionais.

Durante a mesa redonda, sob mediação do doutorando Giovane Fernandes Oliveira, os professores: Lourenço Chacon (Unesp), Marlete Sandra Diedrich (UPF) e Gabriela Maria de Oliveira-Codinhoto (UFAC) discutiram, sob diferentes pontos de vistas, como o uso da língua, especialmente o da fala e o da escrita, colaboram para a constituição da criança como falante e escrevente a partir da observação de produções linguísticas iniciais.

Em sua fala de abertura, o professor Lourenço Chacon (Unesp) indaga se dados não convencionais da escrita infantil podem levantar questões acerca das relações entre a fala e a escrita e para quais questões da aquisição da escrita tais dados podem apontar.

A partir disso, o debatedor apresentou conceitos-chave sobre a fala e a escrita. O professor realizou um percurso teórico conceituando a fala desde uma perspectiva biomecânica, definida como um ato motor, até uma perspectiva textual interativa, definida como um ato de produção textual. Do mesmo modo, a escrita é conceituada desde um código linguístico, em uma perspectiva mais formal, até um ato de produção textual, em uma perspectiva interativa. Nesse ângulo, o professor assume uma perspectiva em que as relações entre fala e escrita são vistas sob o viés de uma abordagem linguístico-discursiva, pois envolvem dois planos essenciais da linguagem: a língua e as práticas discursivas (orais e letradas).

Outra conceituação importante é a diferença entre fala/oralidade e escrita/letramento. Chacon afirma que fala e escrita são produtos linguísticos sob forma de enunciados, enquanto oralidade e letramento são as práticas discursivas que regulam a produção e a circulação de enunciados falados e escritos, respectivamente. Vale destacar que esses planos fazem parte de um fenômeno complexo: 


\section{REVISTA DA ABRALIN}

a organização de enunciados linguísticos, produzidos com base em determinada semiose (acústicoauditiva e gráfica-visual), regulada por práticas discursivas.

$\mathrm{Na}$ análise, o professor destaca algumas estruturas não convencionais de um texto produzido por uma criança da primeira série do ensino fundamental. Nesse sentido, são observados a segmentação das palavras inpe e en pé e a ortografia da palavra cansar. Tal reflexão é formulada com o objetivo de refletir que, por um lado, na escrita da criança, há pistas de práticas da oralidade, representadas pelas grafias cançar e inpe, e, por outro lado, há também nessa escrita marcas de práticas de letramento, representadas pelas convenções ortográficas, como o acento gráfico na palavra en pé.

Lourenço Chacon encerra sua fala afirmando que os dados não convencionais da escrita infantil levantam questões sobre a fala e a escrita, na medida que indicam um atravessamento do escrevente por práticas de oralidade e letramento, bem como conflitos em relação àquilo que deve orientar sua escrita, que são vistos como marcas da subjetividade do escrevente, isto é, o modo como ele se inscreve na sua escrita. Por fim, Chacon afirma que esses dados da aquisição apontam para características de enunciados falados e escritos projetados na escrita inicial da criança, como resultado das práticas de oralidade e letramento pelas quais ela transita.

A segunda convidada para esta mesa é a professora Marlete Sandra Diedrich (UPF), que abordou o tema da aquisição da linguagem como uma experiência de significação, apoiada na perspectiva enunciativa de Benveniste. A pesquisadora procede a tal abordagem a partir de três pontos: a criança fala com outros que falam, a criança se constitui como falante de uma língua e a criança apreende o mundo por meio da fala.

A apresentação parte do princípio de Benveniste (2005) que coloca em foco uma experiência que se dá no simbólico da língua, unindo o homem, a língua e a cultura e permitindo à criança a consciência do meio social no qual ela está inserida. Desse modo, a criança se apropria da língua para viver suas experiências de significação com os outros via discurso.

A partir dessas reflexões, a professora apresenta a pesquisa que desenvolveu com duas crianças: Antônia (5 anos) e Lulu (1 ano e meio). Foram observados dois momentos, com intervalo de seis meses entre cada um, em que a irmã mais velha lia histórias infantis para a irmã mais nova. Nesses recortes, foram observados os fatos da linguagem que revelam as relações da criança com o emprego da língua e suas implicações na constituição da criança como falante. Destacamos, a seguir, os principais pontos abordados pela pesquisadora.

O primeiro ponto aborda a questão da intersubjetividade, desenvolvida a partir dos estudos de Benveniste, que afirma que a criança, assim como os adultos, também fala com outros que falam. Conforme a análise de Diedrich, no primeiro recorte, isso é muito claro, uma vez que há um investimento da irmã mais velha, que está lendo, para convocar a atenção da outra com o objetivo de que ambas vivam essa experiência da leitura. Em contrapartida, no segundo recorte, percebemos um movimento no curso da aquisição: a irmã mais nova deixa a posição de ser convocada, ao utilizar algumas formas que se assemelham à estrutura linguística, para, então, convocar a irmã mais velha.

No segundo ponto, Diedrich destaca a constituição da criança como falante de uma língua. De acordo com o princípio da subjetividade, a criança assume seu lugar no mundo pela linguagem, o 


\section{REVISTA DA ABRALIN}

que foi observado nos dados dos recortes em que as duas crianças estão se deslocando no mundo por meio de arranjos particulares da língua, utilizando-a à sua maneira. Vale destacar uma convergência entre esses dois pontos: esse uso particular da linguagem leva a irmã mais velha a buscar significação na fala da irmã mais nova, isto é, há uma influência do outro nessa subjetividade.

No terceiro ponto, a pesquisadora afirma que a criança apreende o mundo por meio da fala, ou seja, a criança entra em contato com a língua em situações específicas de uso, vivenciando determinados esquemas culturais. As crianças nos dois recortes assumem a língua a partir de determinados valores já dados pela sociedade: por exemplo, o modo como a irmã mais velha mobiliza os arranjos vocais durante a leitura para a irmã mais nova, alterando sua entonação, revela a vivência de um esquema cultural.

Encerrando sua fala, a debatedora converge os três pontos apresentados destacando que, "na relação com o outro, com uma maneira particular de estar na língua, a criança apreende o mundo e se manifesta na realização desta língua na fala", construindo, assim, uma experiência de significação.

A última convidada da mesa é a professora Gabriela Maria de Oliveira-Codinhoto (UFAC), que apresentou uma proposta de análise funcionalista de textos infantis, produzidos por dois alunos ao longo do Ensino Fundamental I, em que focalizou o uso de orações relativas (ORs).

Por se tratar de uma análise funcionalista, a noção de língua concebida é a de um instrumento de interação social em que as estruturas linguísticas são observadas de acordo com dados reais de fala. Além disso, a aquisição da linguagem é vista como um processo de desenvolvimento ou aprendizagem.

O estudo apresentado busca hipóteses que expliquem a distribuição da frequência de orações relativas em textos infantis a partir da análise de produções textuais de dois alunos, evidenciando: a extensão, o tipo de oração, o tipo de conexão entre as partes e as estratégias de composição textual. A partir desses dados, os textos foram comparados em busca de generalizações pertinentes.

A pesquisadora acompanhou os dois alunos ao longo dos quatro anos do Ensino Fundamental I e percebeu um aumento no número de ORs na composição dos textos ao longo dos anos.

Com a análise dos textos, foi possível notar uma evolução na escrita dos alunos. Ambos passaram de construções com enunciados curtos, orações truncadas e justapostas para textos com enunciados longos, orações complexas e refinamento de estratégias de articulação/progressão textual, como parágrafos com unidades temáticas, além do aumento do número de orações relativas.

Nesse sentido, foi observado que, nas primeiras produções, os escreventes não buscavam situar o leitor em relação ao enredo ou ao propósito comunicativo do texto, devido à falta de experiência com as produções textuais e ao processo de alfabetização ainda em andamento. No entanto, nas produções finais, há uma maior preocupação no estabelecimento de um contexto interacional, que, além de alterar a carga informacional desses textos, também colabora para o aparecimento de estruturas linguísticas mais complexas.

A discussão realizada nesta mesa redonda teve um papel fundamental nos estudos de aquisição da linguagem. A apresentação de questões relevantes sobre a fala e a escrita infantis, a partir de diferentes pontos de vista, traz a possibilidade de desdobramentos de pesquisas 


\section{REVISTA DA ABRALIN}

futuras na área que podem colaborar para a maior compreensão desse processo complexo que é a aquisição da linguagem.

\section{REFERÊNCIAS}

A criança e o uso da língua: fala, escrita e suas relações na aquisição da linguagem. Mesa redonda mediada por Giovane Fernandes Oliveira e apresentada por Lourenço Chacon, Marlete Sandra Diedrich e Gabriela Maria de Oliveira-Codinhoto [s.l., s.n], 2020. 1 vídeo (2h 01 min 35s). Publicado pelo canal da Associação Brasileira de Linguística. Disponível em: https://www.youtube.com/watch?v=fP2o-hF7jtg. Acesso em: 17 jul 2020.

BENVENISTE, Emile. Problemas de Linguística Geral I. 5. ed. Campinas: Pontes, 2005. 